\title{
Impact of Augmented Reality Characteristics on Retail Brand Equity
}

\author{
Jinfeng $\mathrm{Wu}^{1}$ and Jiao Dong ${ }^{1, *}$ \\ ${ }^{1}$ School of Management, Wuhan Textile University, Wuhan 430200, China \\ *Corresponding author.Email: JOANNA0068@163.com
}

\begin{abstract}
With the rise of $5 \mathrm{G}$ and mobile shopping, the failure to physically experience products has led to high return rates and negative word-of-mouth for retailers. As a result, many Chinese retailers have been offering augmented reality services to customers to improve their shopping experience. This study aims to investigate the mechanism of augmented reality (AR) characteristics on retail brand equity in the context of retailing. Accordingly, the authors construct a conceptual framework in which AR characteristics affect brand associations and retail brand equity. The empirical tests using the structural equation model method also support the research hypotheses. The results reveal that two AR characteristics-environment embedding (EE) and simulated physical control (SPC)-can positively affect retail brand equity through brand associations. Furthermore, product involvement moderates the effect of EE and SPC on brand associations positively. The findings expand brand equity theory in the field of augmented reality marketing.
\end{abstract}

Keywords: Augmented reality characteristics, brand associations, retail brand equity, situated cognition

theory, product involvement

\section{INTRODUCTION}

Scholz and Smith [1] pointed out that retailers can leverage $\mathrm{AR}$ to craft immersive brand experiences and allow customers to experience products and spaces in novel ways. This requires retailers to provide customers with high-quality AR experiences. For example, the cosmetics retailer Sephora has adopted AR service strategies successfully and the quantity of its visitors dramatically increased. A female customer can check how different cosmetics items dress up her face and examine the details in real-time from different angles of view by moving her head [2]. However, we found that many Chinese retailers' AR marketing strategies typically fail to boost their brand appeal due to weak augmented reality experiences.

The success of AR service strategies depends on whether the value of a retailer's core brand asset-retail brand equity is increased. Retail brand equity can help retailers build and maintain competitive advantage and improve business performance [3]. But so far, no study has investigated the mechanism of how augmented reality characteristics affect retail brand equity.

Yoo and Donthu [4] proved that perceived marketing stimulation significantly affects the dimensions of retail brand equity. Accordingly, as a special type of marketing stimulation, do AR characteristics have similar effects on retail brand equity? How do AR characteristics affect retail brand equity? Does product involvement moderate the relationship between AR characteristics and brand associations? To answer these questions, this study investigates the relationships between AR characteristics and retail brand equity. The findings will provide guidance for retailers to build retail brand by designing immersive AR experiences.

\section{CONCEPTUAL FRAMEWORK}

Based on the "Marketing Activities-Dimensions of Brand Equity-Overall Brand Equity" model proposed by Yoo and Donthu [4], this study presents a conceptual framework as shown in Figure 1. First, we replace the dimensions of brand equity with brand associations. Second, according to the proposal of Hilken et al [5], we replace marketing activities with two AR characteristics: environment embedding and simulated physical control. We assume that both characteristics have significant effect on brand associations, which in turn leads to higher level of overall retail brand equity. Third, we introduce a moderating variable - product involvement into our conceptual model to evaluate whether the effects of AR characteristics on brand associations are subject to different products. 


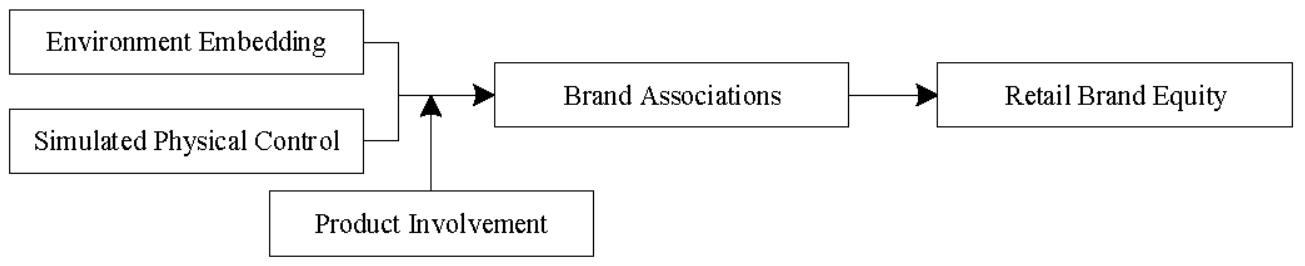

Figure 1. Conceptual framework

\subsection{Retail Brand Equity}

Retail brand equity (store equity) is defined as the differential effect of store knowledge on customer response to the marketing activities of the store [6]. In this study, retail brand equity is a unidimensional concept according to White and Mathews [7]. Existing studies have identified four dimensions of retail brand equity, that is, retail brand awareness, retail brand associations, perceived quality, and retail brand loyalty. Brand awareness, brand associations and perceived quality constitute customer-based brand knowledge while brand loyalty reflects the relationship between customers and brands. In addition, brand associations play an important role in the formation of customers' differential response [8]. Brand associations refer to anything linked to the customer's memory of the retail brand [3], which are the attributes and benefits associated with a retail brand name perceived by customers [8]. Furthermore, Cho et al [9] divided brand associations into three dimensions: cognitive, affective and sensory associations. Cognitive associations refer to consumers' thoughts about a brand in terms of product attributes, services, performance and symbolic meaning [18]. Affective associations reflect a customer's commitment to the brand and enjoyment from interacting with the brand [9]. Sensory associations capture visual, olfactory, auditory and tactile sensations related to the brand and its product [9].

\subsection{Augmented Reality Characteristics}

$\mathrm{AR}$ is "a technology which allows computer generated virtual imagery to exactly overlay physical objects in real time" [10]. AR marketing is a strategic concept that integrates digital information or objects into the subject's perception of the physical world, often in combination with other media to achieve organizational goals [11]. AR-based shopping is considered as a service experience, enabling customers to see how products fit them personally or in their environments [5]. As a new marketing approach for enterprises, AR marketing can extend established marketing approaches such as advertising, content marketing and storytelling [11].

Drawing on situated cognition theory, Hilken et al [5] concluded two aspects of customer experience of AR marketing, that is, embedding and embodiment. According to situated cognition theory [5], customers' information processing is embedded in their physical environment and embodied through physical simulations and actions. In other words, situated cognition enables customers to learn more about the value of products and services when they integrate information about products and services in realtime within the immediate decision context (i.e., are embedded), allow for physical interaction with a product or service (i.e., are embodied) [12]. Based on situated cognition theory, Hilken et al [5] proposed two AR characteristics: environmental embedding (EE) and simulated physical control (SPC). EE was defined as the visual integration of virtual content into a person's realworld environment. SPC was defined as the ability of AR to simulate physical control over an offering (e.g., moving, rotating).

\section{RESEARCH HYPOTHESES}

Fan et al [13] found that EE and SPC can significantly improve customers' cognitive fluency. In other words, when the level of EE and SPC is high, the way of information processing about products and services seems more realistic and familiar and requires fewer cognitive resources. Thus, more cognitive resources are available for building cognitive associations. Song et al [14] found that EE and SPC positively affect customers' decision comfort by evoking customers' perceived immersion. Decision comfort refers to the degree of ease, contentment, and wellbeing one feels when making a specific decision and is a soft-positive emotion [15]. AR services can provide the visual sensory stimulus that $A R$ integrates the virtual product into the real-world environment. By touching the interactive display screen, customers are able to control the virtual product which has the same size as the actual one. There are visual, tactile and other sensory stimuli in the AR-based shopping environment, providing a more realistic experience [16]. As a result, customers are more likely to build a brand-related memory in the cognitive, affective, and sensory aspects when EE and SPC are at a high level. Thus,

$\mathrm{H1}$ : Environmental embedding (EE) has a positive impact on brand associations.

H2: Simulated physical control (SPC) has a positive impact on brand associations.

According to Cho et al [9], cognitive, affective, and sensory associations have positive impacts on overall retail 
brand equity. Brand equity is at least partially driven by the nature of the brand associations which make up the brand image [8]. High levels of brand associations play an important role in determining the differential response that make up brand equity [8]. Thus,

H3: Brand associations has a positive impact on retail brand equity.

Product involvement is defined as the extent to which the product is important and interesting to the customer [17]. Customers with high involvement will be more motivated to invest the effort in processing information about the brand and its products deeply [17], and thus more likely to shape associative memories about the brand in their minds. In this case, customers' perceived EE and SPC will have stronger impacts on building brand associations. Thus,

H4: The effect of AR characteristics (a: environment embedding, b: simulated physical control) on brand associations is greater for highly involved customers than for less involved customers.

\section{METHODOLOGY}

\subsection{Samples}

Two online brand stores on the Taobao retail application were selected as stimuli, including Ray-Ban and Schwarzkopf. Products they sell were respectively sunglasses and hair dyes. Their AR service online links served as experimental links. Students who have used AR technology in shopping were selected to participate in this study. Respondents were asked to fill in a questionnaire after the experiment. A total of 602 responses were obtained. Elimination of incomplete responses left 520 eligible responses for analysis. $23.5 \%$ of the respondents were men and $76.5 \%$ were women. $99.4 \%$ were between 18-34 years old. The online brand stores consist of Schwarzkopf $(\mathrm{N}=347)$ and Ray-Ban $(\mathrm{N}=137)$.

\subsection{Questionnaire Design}

All measurement scales were verified by previous empirical studies. All items were on a seven-point Likert scale rating from $1=$ not at all (strongly disagree) to $7=\mathrm{a}$ lot (strongly agree).

\section{EMPIRICAL ANALYSIS AND RESULTS}

\subsection{Reliability and Validity Analysis}

The results of exploratory factor analysis (EFA) showed that the Cronbach's $\alpha$ coefficients ranged from 0.758 to 0.905 , and the composite reliability scores ranged from 0.760 to 0.946 for all constructs. The results of confirmatory factor analysis (CFA) showed that all the standardized factor loadings were higher than 0.603 , and the average variance extracted ranged from 0.561 to 0.854 . Thus, the scale for constructs appears to exhibit satisfactory internal consistency reliability and convergent validity.

\subsection{Path Analysis}

Structural equation model (SEM) analysis as supplied by AMOS 24.0 was used to estimate parameters of the model in Figure 2. The structural model had good fit indices: $\chi 2 / \mathrm{df}=3.784, \quad \mathrm{RMSEA}=0.073, \quad \mathrm{CFI}=0.901, \quad \mathrm{IFI}=0.901$, $\mathrm{NFI}=0.870, \mathrm{CFI}=0.916, \mathrm{GFI}=0.842, \mathrm{AGFI}=0.811$. All path coefficients were significant. EE had a positive impact on brand associations $(\beta=0.253, \quad \mathrm{p}<0.001)$. SPC had a significant positive impact on brand associations $(\beta=0.487$, $\mathrm{p}<0.001)$. The effect of brand associations on retail brand equity was significant $(\beta=0.837, \mathrm{p}<0.001)$. Therefore, $\mathrm{H} 1$, $\mathrm{H} 2$, and $\mathrm{H} 3$ were supported.

The moderating effect depends on whether the interaction between the independent variable and the moderating variable is significant. If the $\mathrm{P}$-value is lower than 0.05 , it indicates that there is a significant moderating effect. The results showed that the interaction between $\mathrm{EE}$ and product involvement affected brand associations positively $(\beta=0.163, p<0.001)$. The interaction between SPC and product involvement also had a positive effect on brand associations $\quad(\beta=0.977, \quad \mathrm{p}<0.001)$. Thus, product involvement moderated the relationship between AR characteristics and brand associations significantly. H4 was supported.

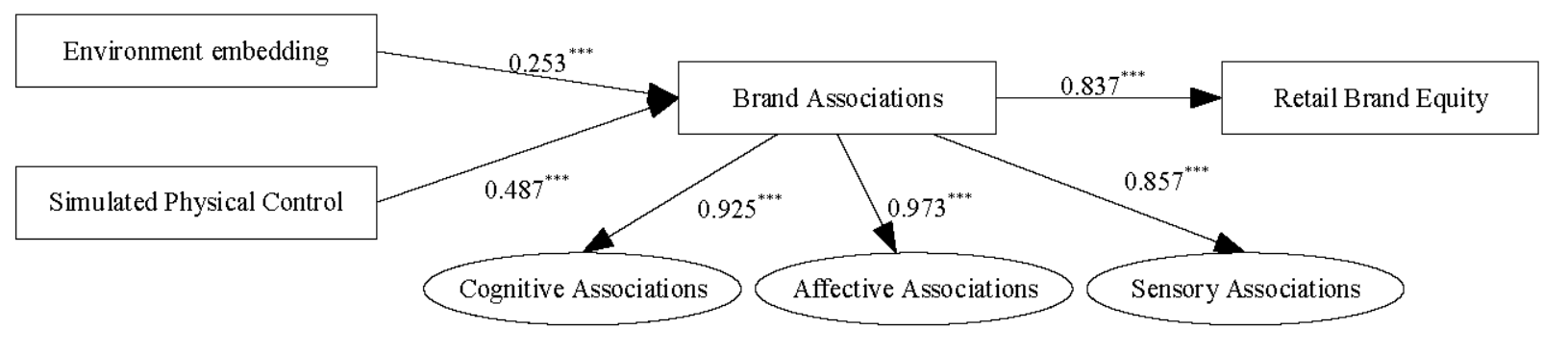

Figure 2. Path analysis 


\section{CONCLUSION}

This study explored the effect of AR characteristics on retail brand equity through brand associations. The conclusions were as follows:

First, retail brand associations, as reflected by cognitive, affective and sensory associations, have positive effects on retail brand equity. As the vital elements of retail brand equity, positive retail brand associations are more likely to associate with preferred retailers than non-preferred retailers. Retailer managers can take retail brand associations as a signal of retail brand equity and invest on it to build retail brand equity.

Second, two characteristics of AR, that is, EE and SPC, positively affect retail brand associations. Optimizing these AR characteristics should be feasible and important approach to build retail brand equity. Thus, retailer managers should make full use of them when carrying AR marketing.

Finally, product involvement positively moderates the effect of EE and SPC on brand associations. In order to promote retail brand equity effectively, retailer manager should capitalize not only characteristics of AR but also the product types subject to which the effects of AR characteristics on brand associations may vary.

\section{ACKNOWLEDGMENT}

This research was supported by the Humanities and Social Science Project of Ministry of Education of China (Grant No. 17YJA630108), the National Social Science Fund of China (Grant No. 20BGL122) and the National Natural Science Foundation of China (Grant No. 71962002).

\section{REFERENCES}

[1] Scholz J, Smith A N. Augmented reality: Designing immersive experiences that maximize customer engagement[J]. Business Horizons, 2016, 59(2):149161.

[2] Deloitte Consulting. <Augmented shopping: The quiet revolution $>[\mathrm{EB} / \mathrm{OL}]$.

https://www2.deloitte.com/us/en/insights/topics/emergin g-technologies/augmented-shopping-3d-technologyretail.html,2020.

[3] Pappu, R., Quester, P. A. customer-based Method for retail brand equity Measurement: Results of an Empirical Study[J]. Journal of Retailing and customer Services, 2006, 34(13): 317-329.

[4] B. Yoo, N. Donthu, and S. Lee. An examination of selected marketing mix elements and brand equity[J]. Academy of Marketing Science, 2000(28):195-211.
[5] Hilken T, de Ruyter K, Chylinski M, et al. Augmenting the eye of the beholder: exploring the strategic potential of augmented reality to enhance online service experiences[J]. Journal of the Academy of Marketing Science, 2017, 45(6): 884-905.

[6] Hartman K B, Spiro R L. Recapturing store image in customer-based store equity: a construct conceptualization[J]. Journal of Business Research, 2005, 58(8):1112-1120.

[7] White, R. C., Mathews, S. J., Voorhees, C. M. The Effects of Service on Multichannel Retailers` Brand Equity[J]. Journal of Service Marketing, 2013, 27(4): 259-270.

[8] Keller, K. L. Conceptualizing Measuring and Managing Customer-based Brand Equity[J]. Journal of Marketing, 1993, 57(1):1-22.

[9] Cho E, Fiore A M, Russell D W. Validation of a Fashion Brand Image Scale Capturing Cognitive, Sensory, and Affective associations: Testing Its Role in an Extended Brand Equity Model[J]. Psychology and Marketing, 2015, 32(1):28-48.

[10] Zhou, F., Duh, H.B.L., Billinghurst, M., 2008. Trends in augmented reality tracking, interaction and display: a review of ten years of ISMAR. In: Proceedings of the 7th IEEE/ACM International Symposium on Mixed and Augmented Reality. IEEE Computer Society, pp. 193-202.

[11] Rauschnabel P A, Felix R, Hinsch C. Augmented reality marketing: How mobile AR-apps can improve brands through inspiration[J]. Journal of Retailing and customer Services, 2019, 49: 43-53.

[12] Hilken T, Heller J, Chylinski M, et al. Making omnichannel an augmented reality: the current and future state of the art[J]. Journal of Research in Interactive Marketing, 2018.

[13] Fan X, Chai Z, Deng N, et al. Adoption of augmented reality in online retailing and customers' product attitude: A cognitive perspective[J]. Journal of Retailing and customer Services, 2020, 53: 101986.

[14] Song H K, Baek E, Choo H J. Try-on experience with augmented reality comforts your decision[J]. Information Technology \& People, 2019.

[15] Parker J R, Lehmann D R, Xie Y. Decision Comfort[J]. Journal of customer Research, 2016, 43(1). 
[16] Huang T L, Liu F H. Formation of augmentedreality interactive technology's persuasive effects from the perspective of experiential value[J]. Internet

Research, 2014.

[17] Malär L, Krohmer H, Hoyer W D, et al. Emotional Brand Attachment and Brand Personality: The Relative
Importance of the Actual and the Ideal Self[J]. Journal of Marketing, 2011, 75(4):35-52.

[18] Friedmann, R. and Lessig, V.P. Psychological meaning of products and product positioning[J]. Journal of Product Innovation Management, 1987, 4(4):265273. 